Submission ID: 43818

\title{
Formation Conditions of Carbonate Reservoirs in offshore of the Middle
} Caspian Petroleum Basin

A. Maksiutova* (Schlumberger Logelco Inc.), A. Aseev (Schlumberger Logelco Inc.), A. Blank (Schlumberger Logelco Inc.)

\section{SUMMARY}

Mesozoic deposits in the Middle Caspian Sea have interested petroleum companies during long time with rich hydrocarbon potential, but they remain insufficiently studied for deep understanding of geological structure exist deposits and perspective objects.

The Upper Jurassic carbonate reservoirs, whose productivity is mainly associated with the secondary porosity, is an intricate object of study at one of the Karpinsko-Mangyshlak deposits. The complexity of the formation condition reconstruction of carbonate reservoirs is due to the large number of geological factors affecting the formation of the original void space, from which formation of the secondary porosity in future depends.

Sedimentation analysis of the Upper Jurassic carbonate reservoirs distribution in offshore of the Middle Caspian petroleum basin represented their confinement to the shallow inner ramp facies (lagoon and sandbanks) and the mid ramp facies.

In such in manner, with the knowledge of the geological structure of the area, using a technique of separate core data by lithotypes, well loging and FMI data, by combining them with using a map of attributes extracted from the acoustic impedance cube, a facial map can be constructed to better orientate the geological development of the area and the predict of productive zones. 
Условия формирования карбонатных резервуаров акваториальной части одного из месторождений Среднекаспийского НГБ

\author{
А.В.Максютова*, А.А.Асеев, А.М.Бланк (Шлюмберже)
}

\title{
Введение
}

Благодаря геофизическим методам и поисковому бурению в акватории Средне-Каспийского НГБ за последние 15-20 лет открыт ряд крупных нефтегазовых месторождений и отдельных перспективных структур (им. Ю.Корчагина, Ракушечное, им. Филановского, Морское, им. Ю. Кувыкина, Хвалынское, Центральное) и получен значительный прирост запасов нефти и газа. Несмотря на это, изученность мезозойских отложений в акватории Среднего Каспия остается недостаточной для понимания геологического строения открытых залежей и перспектинвых объектов.

Верхнеюрские карбонатные резервуары, продуктивность которых связана, главным образом, со вторично образованной пористостью, являются сложным и интересным объектом изучения на одном из месторождений Карпинско-Мангышлакской зоны. Сложность реконструкции условий накопления карбонатных коллекторов обусловлена большим числом геологических факторов, влияющих на образование первоначального пустотного пространства, от строения которого зависит дальнейшее формирование вторичной пористости. Проведение седиментационного анализа позволит получить более глубокое понимание механизма образования карбонатных коллекторов и в дальнейшем улучшить точность прогноза резервуаров в промышленно значимых залежах нефти и газа в исследуемом районе.

\section{Методика исследований}

Построение седиментационной модели базируется на основе изучения структурных, литологических, физических характеристик, в том числе особенностей распространения пустотного пространства. В качестве исследуемого материала ипользуются данные керна, геофизические исследования скважин (ГИС) и пластовый электрический микросканер (FMI).

Керновые данные несут в себе информацию о структурно-текстурных признаках, литологическом составе, наличии включений, каверн, трещин, информацию о фильтрационноемкостных свойствах породы [Жемчугова, 2014]. Во всех скважинах керн отобран в продуктивном верхнеюрском интервале и полностью присутсвует в верхнетитонской продуктивной пачке. Согласно анализу кернового материала разрез составляют микромелкозернистые доломиты с реликтовой и биоморфной структурой в прослоях в отдельных интервалах. Присутствуют следовые каверны, сходные по конфигурации с раковинами брахиопод, фрагментами створок пелеципод и раковинок гастропод. Редко встречаются трещины субвертикальные, заполненные ангидритом, главным образом.

Информация о важных интерпретируемых параметрах, таких как пористости и проницаемости были получены в процессе работы петрофизиков из данных стандартного каротажа с использованием основных методов гамма-каротажа, гамма-гамма плотностного каротажа и акустического каротажа. Данные пластового микроимиджа позволили определить природу трещин, их распространенность, форму и размер каверн.

На основе методики, описанной в учебном пособии В.А. Жемчуговой 2014 года, был проведен седиментационный анализ по исследуемому району. На первом этапе анализа с упором на керновый материал в разрезе были выделены хроностратиграфические поверхности, согласно принципам выделения одновозрастных отложений, развивающихся в генетически связанных обстановках осадконакопления и разделенных поверхностями затопления.

В соответствии с вышеизложенным материалом на основе использования данных керна ГИС и FMI, в продуктивном интервале была построена 2D-седиментационная модель обстановок 
осадконакопления карбонатного рампа (рисунок 3). На основе структурных и текстурных признаков в карбонатных породах были выделены фации внутреннего и среднего рампа.

Отложения внутреннего рампа в данном районе представляют собой мелководно-морские микро-мелкозернистые фораминиферовые доломиты и известняки, накапливающиеся в условиях практически непрерывной волновой деятельности и течений. Визуальный анализ керна и наблюдение за кривой ГИС объема глин позволяют отнести карбонатные отложения внутреннего рампа к мадстоунам, согласно приведенной на рисунке 1 классификации. Наблюдаемые в срезе керна и FMI интервалы, содержащие незначительное количество раковинного реликтового материала и общие структурно-текстурные признаки позволяют предположительно отнести данные отложения внутреннего рампа к нижней литорали.

Для отложений среднего рампа характерно преобладание штормовых процессов, что подтверждается керновым материалом, на срезе которого видны останки раковинного детрита, среди данных FMI можно выделить каверны, образовавшиеся в результате растворения раковин пелеципод и гастропод. Структурно-текстурные признаки отложений среднего рампа соответствуют мелко-среднезернистым доломитам с прослоями известняков, определяемых как вакстоуныс с многочисленными останками кальцитного скелетного материала и биотурбацией. Также в срезе керна можно рассмотреть водорослевые текстуры, предположительно отвечающие невысоким полигональным карбонатным постройкам, сложенными губково-кораллово-микробиальными образованиями. Текстурно-структурные признаки литотипов, глубина и условия жизнедеятельности позволяют отнести эти отложения к сублиторали.

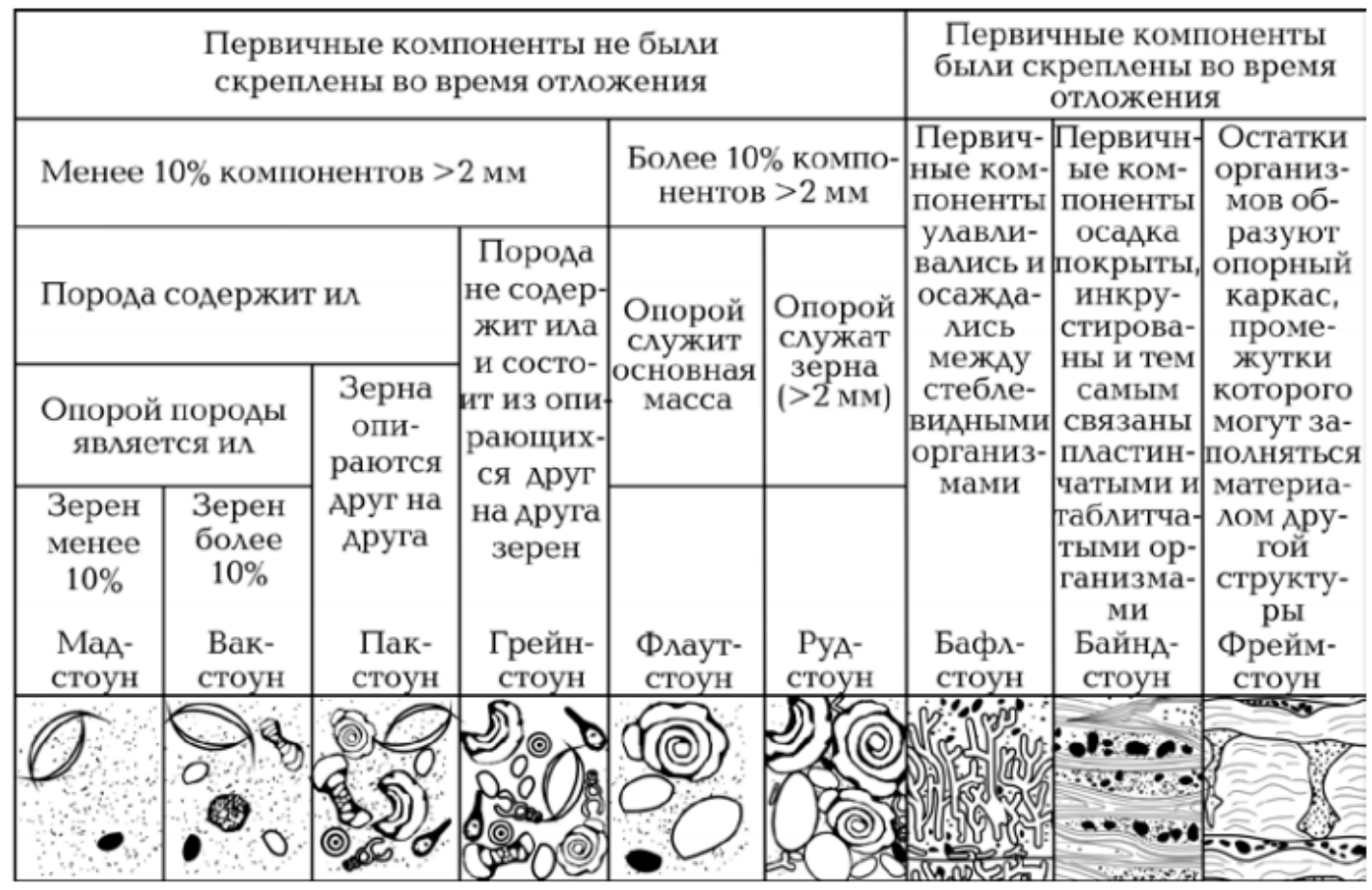

Рисунок 1 Структурная классификация карбонатных пород (Р.Данем, А.Эмбри, Дж. Кловен).

После выделения литотипов по керновому материалу в имеющихся скважинах на основе структурно-текстурных признаков был проведен анализ сопоставления литотипов со значениями физических величин по карте атрибутов. Карта атрибутов была получена из куба акустического импеданса. 
Различные цвета, характеризующие разрез куба акустического импеданса (на рисунке 2) показывают изменение скорости продольной волны Vp и плотности RHOB: фиолетовые и синие цвета обозначают высокие значения акустического импеданса, красные и желтые цвета низкие значения акустического импеданса.
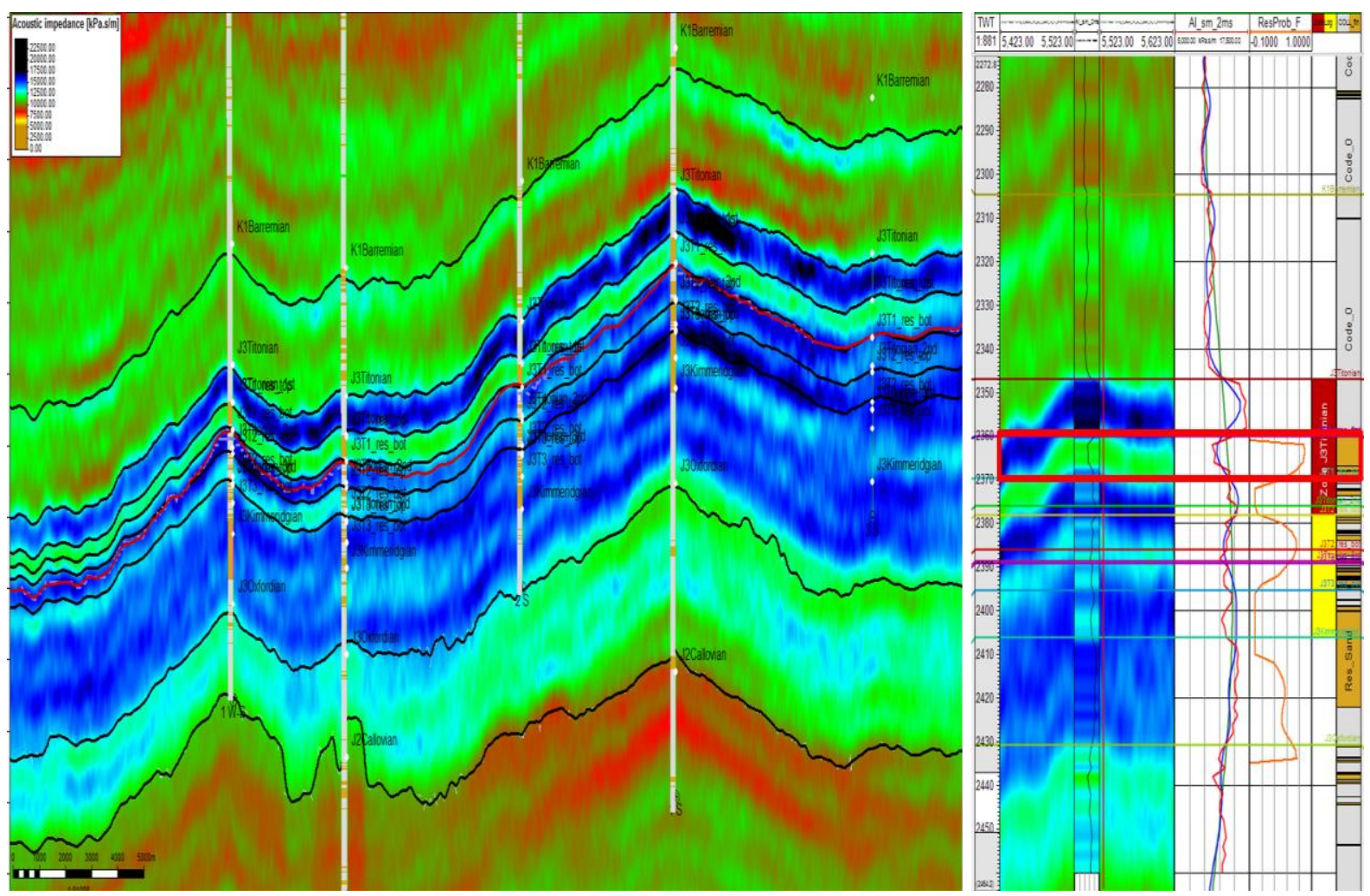

Рисунок 2 Композитный разрез значений акустического импеданса верхнетитонского интервала. Справа показано сопоставление синтетической кривой вероятности коллектора, полученной из куба акустического импеданса, с кривой значений акустического импеданса в одной из скважин. В красной рамке выделена верхняя пачка верхнетитонского интервала, по которому была построена фациальная карта.

Хорошая корреляция между синтетической кривой по кубу акустического импеданса с кривой ГИС акустического каротажа в скважинах в верхней пачке верхнетитонских отложений позволяет говорить о высокой вероятности расположения коллекторов, что дает нам основание использовать карту атрибутов (рисунок 3), извлеченную из этого куба акустического импеданса.

Как видно на рисунке 3 на карте атрибутов можно выделить три зоны с различными значениями акустического импеданса. Зона с относительно высоким значением импеданса отвечает накоплению микритовых доломитов (мадстоунов) нижней литорали, что не противоречит ориентировочному местоположению береговой линии в соответствии с региональными данными развития Среднекаспийского НГБ. Далее в сторону моря выделяются более относительно глубоководные отложения сублиторали, с выделенными по акустическому импедансу примерными зонами распространения вакстоунов, грейнстоунов и пакстоунов, которым соответствуют пониженные значения акустического импеданса. Совсем низким значениям акустического импеданса соответствуют небольшие карбонатные постройки относительно глубоководных отложений среднего рампа, что подтверждается скажинными данными.

Измерения ФЕС на образцах керна в верхней пачке верхнетитонского интервала показывают высокие значения пористости $(17-22 \%)$ в скважинах A, C, D, что также связано с 
дополнительным образованием пустотного пространства посредством локализованной доломитизации.
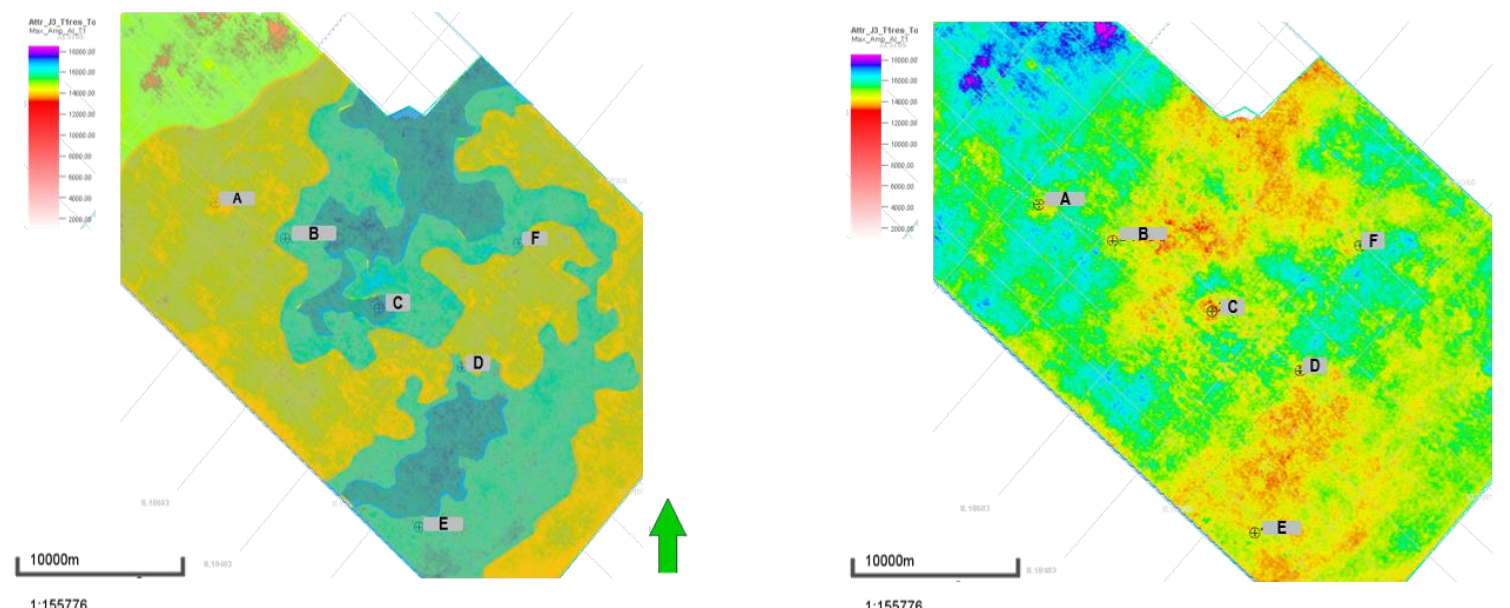

Отложения внутреннего рампа: нижняя литораль

Мадстоуны

Отложения среднего рампа: сублитораль
Вакстоуны
Грейнстоуны и пакстоуны
Полигональные карбонатные структуры
(байндстоуны)

Рисунок 3 Слева - фаииальная карта отложений верхней продуктивной пачки верхнего титона, справа - карта атрибутов, извлеченная из куба акустического импеданса.

\section{Выводы}

Анализ распространения верхнеюрских карбонатных коллекторов верней пачки верхнетитонского интервала месторождения акваториальной части Среднекаспийского НГБ показал приуроченность их к мелководным фациям внутреннего (отложениям нижней литорали) и среднего рампа (отложениям сублиторали).

Таким образом, учитывая знания о геологическом строении района, используя методику выделения литотипов по керновому материалу, ГИС и FMI, посредством комплексирования их с картой атрибутов, извлеченной из куба акустического импеданса можно построить карту фациального районирования для лучшего ориентирования в геологическом развитии площади и прогноза продуктивных областей.

\section{Библиография}

В тексте:

[Жемчугова, 2014]

[Пискунов., 2013]

\section{В списке:}

1, Глумов И.Ф. и др., [2004] «Региональная геология и нефтегазоносность Каспийского моря», Москва, ООО «Недра-Близцентр»

2, Жемчугова В.А., [2014] «Практическое применение резервуарной седиментологии при моделировании углеводородных систем», Москва, Российский государственный университет нефти и газа имени И.М, Губкина,.

3, Пискунов В.К., [2013], «Строение и история формирования верхнеюрских отложений района плато Демерджи и плато Тирке (Горный Крым)». Автореферат диссертации на соискание ученой степени кандидата геолого-минералогических наук. 


\section{EAGE}

\section{References}

1. Glumov I.F et al., [2004] «Regional Geology and Petroleum Potential of the Caspian Sea», Moscow, «Nedra-Blizcenter»

2. Zhemchugova V.A., [2014] «Practical Application of Reservoir Sedimentology in the Modeling of Hydrocarbon Systems», Moscow, Gubkin Russian State University of Oil and Gas.

3. Piskunov V.K., [2013], «Structure and history of the formation of Upper Jurassic deposits in the Demerdzhi plateau region and the Tirke plateau (Mountain Crimea)», the dissertation author's abstract for the $\mathrm{PhD}$ of geology-mineralogical sciences. 